\title{
Does Subclinical Hypothyroidism Affect Dynamic Thiol / Disulfide Homeostasis and İschemia-modified Albumin Levels in Children?
}

\author{
Serkan Tursun ${ }^{1}$, Aysegul Alpcan ${ }^{1}$, Ayca Torel Ergur ${ }^{2}$, Irfan Karahan ${ }^{3}$, Salim Neselioglu ${ }^{4}$ and Ozcan Erel ${ }^{4}$ \\ ${ }^{1}$ Department of Pediatrics, Faculty of Medicine, Kirikkale University, Turkey \\ ${ }^{2}$ Department of Pediatrics Endocrinology, Faculty of Medicine, Ufuk University, Turkey \\ ${ }^{3}$ Department of Internal Medicine, Faculty of Medicine, Kirikkale University, Turkey \\ ${ }^{4}$ Department of Medical Biochemistry, Faculty of Medicine, Yildirim Beyazit University, Turkey
}

\begin{abstract}
Objective: To determine the effects of subclinical hypothyroidism on oxidative stress in children.

Study Design: A cross-sectional study.

Place and Duration of Study: Department of Paediatrics, Paediatric Endocrinology, and General Outpatient Clinics, Kirikkale University, School of Medicine, from May 2017 to October 2018.

Methodology: This study included 92 subjects aged between 2 and 18 years. The subjects were divided into two groups. Forty-seven children with subclinical hypothyroidism and 45 healthy controls were evaluated. In order to evaluate oxidative damage, native thiol, total thiol, disulfides, their ratios, and ischemia-modified albumin (IMA) levels were compared between the two groups. The relationship between TSH and IMA levels was assessed.

Results: Age and gender were not significantly different in the two groups. Native thiol, total thiol, disulfides and their ratios were similar in the two groups. Ischemia-modified albumin levels were significantly higher in the patient group than the controls $(p<0.001)$. There was no correlation between TSH and IMA levels in the patient group $(r=0.069 p=0.645)$.

Conclusion: Subclinical hypothyroidism may be related to the impairment of IMA, and have a neutral effect on thiol/disulfide balance. Further research is needed to explain the effects of oxidative stress in subclinical hypothyroidism.
\end{abstract}

Key Words: Subclinical hypothyroidism, Childhood, Oxidative stress.

How to cite this article: Tursun S, Alpcan A, Ergur AT, Karahan I, Neselioglu S, Erel O. Does Subclinical Hypothyroidism Affect Dynamic Thiol / Disulfide Homeostasis and İschemia-modified Albumin Levels in Children?. J Coll Physicians Surg Pak 2020; 30(07):726-729.

\section{INTRODUCTION}

Subclinical hypothyroidism (SHT) is a condition with no specific symptoms, which is characterised by an elevated thyroid-stimulating hormone (TSH) level along with normal free triiodothyronine (fT3) and free thyroxine (fT4) levels. Whereas, the prevalence of SHT is approximately $4-20 \%$ in adults, it is less than $10 \%$ in children. ${ }^{.}$Subclinical hypothyroidism is considered a risk factor for overt hypothyroidism, atherosclerosis, and cardiovascular diseases. Thyroid hormones also have a pivotal role in neurological maturation, cardiovascular functions, and linear growth. Subclinical hypothyroidism may affect these conditions and have relevant clinical complications. ${ }^{2,3}$

Hypothyroidism can cause oxidative stress by impairing the balance between oxidant and antioxidant capacities.

Correspondence to: Serkan Tursun, Kirikkale University

E-mail: drtursun@hotmail.com

Received: February 28, 2020; Revised: June 21, 2020;

Accepted: July 02, 2020

DOI: https://doi.org/10.29271/jcpsp.2020.07.726
Thiols are buffers and act as antioxidants. Thiols include sulfhydryl groups that can reduce oxidant agents. This antioxidant mechanism protects the organism from the harmful effects of oxidative damage. ${ }^{4}$

Thiols are converted to disulfides during the reaction and may be converted into thiol groups again. These reactions are termed as the dynamic thiol/disulfide homeostasis. Thiol/disulfide balance is an indicator of oxidativestress.Ischemia-modified albumin (IMA) is a novel biomarker reflecting oxidative damage and ischemia. Ischemia-modified albumin is related to cardiac ischemia as well as non-cardiac pathologies such as renal diseases, peripheral artery disease, and hepatic disease.5-7

This study aimed to determine the effects of subclinical hypothyroidism on thiol/disulfide balance and IMA levels.

\section{METHODOLOGY}

This study included 92 patients aged between 2 and 18 years, who were admitted to the Department of Paediatric Endocrinology, Kırıkkale University School of Medicine, Turkey for TSH elevation during examinations and routine controls. Patients 
with any systemic and/or infectious disease, other endocrinopathies, inflammatory conditions and/or medication use were excluded. A detailed physical examination and anthropometric measurements were performed in all children. The chronological age and body mass index (BMI) were recorded. The reference BMI curves for Turkish children were utilized. ${ }^{8} \mathrm{BMI}$ was calculated with the formula: weight $(\mathrm{kg}) /$ height $x$ height (metres).

SHT was diagnosed on the basis of normal fT4 and fT3 levels along with increased TSH level (mild: $4.5-10$ severe $>10 \mathrm{mIU} / \mathrm{L}$ ). ${ }^{9}$

This cross-sectional designed study included 92 children aged between 2 and 18 years. Forty-seven patients with SHT and 45 healthy subjects (the control group) were evaluated. The control group was matched with the study group for age and gender, and the laboratory parameters (biochemical and hormone assays) were within normal limits in the control group. Total thiol, native thiol, disulfide, disulfide/total thiol, disulfide/native thiol, native thiol/total thiol levels, and ischemia-modified albumin levels were compared between the two groups. The parents of the patients gave informed consent for study participation.

Specimens were collected in the early morning, forthe measurement of thiol/disulfide homeostasis parameters. All samples were centrifuged for $10 \mathrm{~min}$ at $1500 \mathrm{rpm}$ to pick out the serum. Serum dynamic thiol/disulfide homeostasis and ischemia-modified albumin levels were studied with the spectrophotometric method, ${ }^{10}$ an automated clinical chemistry analyser.

Ischemia-modified albumin measurement was performed by a colorimetric assay method that was described by Bar-Or et al. ${ }^{11}$ This method is based on albumin binding to exogenous cobalt. Ischemia-modified albumin results were expressed in absorbance units (ABSUs). The thiol/disulfide parameters and IMA were analysed at Faculty of Medicine, Biochemistry Laboratory, Yildirim Beyazit University.

All data were analysed using IBM SPSS version 25. Shapiro-Wilk test was used to test the normality of data distribution. Quantitative variables with normal distribution were expressed as mean \pm standard deviation and those with non-normal distribution as median (IQR 1st quartile: Q1- 3rd quartile: Q3). Independent samples t-test or Mann-Whitney U-test was used to compare two means of quantitative data. Categorical variables were expressed as frequency and percentage. Chi-square test was used for categorical variables. Pearson's correlation analysis was used to analyse correlations. The $p$-values $<0.05$ were considered statistically significant.

This study was approved by the Institutional Review Board. (Date:16.05.2017 Number: 12/23)

\section{RESULTS}

The mean age of participants was $11.52 \pm 3.99$ years. The study population consisted of 47 girls ( $51.1 \%$ ) and 45 boys (48.9\%). General characteristics and laboratory values of the patient and control groups were shown in Tablel.
There was no statistically significant difference between the two groups with respect to the levels of total thiol level, native thiol level, disulfide level, and their ratios including disulfide/total thiol, disulfide/native thiol, native thiol/total thiol ratios. Ischemia-modified albumin levels were higher in the SHT group than the control group (Table II). There was no correlation between TSH and IMA levels in theSHTgroup ( $r=0.069, p=0.645)$.

Table I: Mean age and thyroid function in children with subclinical hypothyroidism and in the control group.

\begin{tabular}{|l|c|c|c|}
\hline & $\begin{array}{c}\text { Patient group } \\
\mathbf{n = 4 7}\end{array}$ & $\begin{array}{c}\text { Control group } \\
\mathbf{n = 4 5}\end{array}$ & $\mathbf{p}$ \\
\hline Age & $12(8.75-15.13)$ & $\begin{array}{c}11.75 \\
(8.5-15.50)\end{array}$ & 0.72 \\
\hline $\begin{array}{l}\text { Gender: } \\
\text { Birls } \\
\text { Boys }\end{array}$ & $25(53.2 \%)$ & $22(48.9 \%)$ & 0.68 \\
\hline TSH & $22(46.8 \%)$ & $23(51.1 \%)$ & 0.30 \\
\hline
\end{tabular}

Table II: The comparison of the parameters of oxidative stress in subclinical hypothyroidism cases and control groups.

\begin{tabular}{|l|c|c|c|}
\hline & $\begin{array}{c}\text { Patient group } \\
\mathbf{n = 4 7}\end{array}$ & $\begin{array}{c}\text { Control group } \\
\mathbf{n = 4 5}\end{array}$ & $\mathbf{p}$ \\
\hline Albumin, $\mathrm{g} / \mathrm{dl}$ & $4.31(3.90-4.63$ & $4.38(3.95-4.63)$ & 0.708 \\
\hline Total thiol, $\mu \mathrm{mol} / \mathrm{L}$ & $342.71 \pm 77.78$ & $326.45 \pm 75.09$ & 0.311 \\
\hline Native thiol, $\mu \mathrm{mol} / \mathrm{L}$ & $293.83 \pm 66.25$ & $277.14 \pm 71.12$ & 0.247 \\
\hline Disulfide, $\mu \mathrm{mol} / \mathrm{L}$ & $\begin{array}{c}23.40(20.93- \\
28.50)\end{array}$ & $\begin{array}{c}23.20(20.90- \\
27.40)\end{array}$ & 0.848 \\
\hline Disulfide/total thiol & $7.81(6.74-9.40)$ & $\begin{array}{c}8.65(7.17- \\
10.41)\end{array}$ & 0.139 \\
\hline Disulfide/native thiol & $7.07 \pm 1.53$ & $7.78 \pm 2.24$ & 0.079 \\
\hline Native thiol/total thiol & $85.87 \pm 3.06$ & $84.45 \pm 4.48$ & 0.079 \\
\hline Ischemia-modified albumin, $A B S U$ & $1.03 \pm 0.19$ & $0.67 \pm 0.16$ & $<0.001$ \\
\hline
\end{tabular}

\section{DISCUSSION}

Oxidative stress has a key role in various cardiovascular and chronic diseases, and many prospective studies have shown such association. ${ }^{12}$ The present study showed that patients with SHT and healthy subjects had similar dynamic thiol/disulfide parameters. But the patients had higher IMA levels than the healthy controls. IMA may reflect atherogenesis and vascular system injury via oxidative stress. ${ }^{13}$ It is a good biochemical marker for early ischemia such that its level increases in acute coronary syndromes, ${ }^{14}$ acute heart failure, ${ }^{15}$ liver cirrhosis, ${ }^{16}$ diabetes mellitus, ${ }^{17}$ malignancies, ${ }^{18}$ among other disorders. Doğan et al. showed that patients with SHT had higher levels of atherogenic lipids than healthy controls; there was also a significant relationship between TSH levels and the levels of atherogenic lipids. ${ }^{19}$ They emphasised that SHT may create a potential risk for atherogenesis.

Reddy et al. found a higher IMA level in patients with overt and subclinical hypothyroidism than euthyroid controls, and also a significant correlation between TSH and IMA levels in overt hypothyroidism. ${ }^{20}$ However, there was no similar association in SHT patients. They speculated that hypothyroidism may increase oxidative damage to lipids and proteins. Their findings support this data. 
Erem et al. showed that levothyroxine treatment might mitigate lipid peroxidation, oxidative damage, and atherogenesis. ${ }^{21}$ They studied overt and subclinical hypothyroidism patients. Malondialdehyde (MDA) and IMA levels were evaluated before and after hormone replacement therapy. Malondialdehyde level was reduced by treatment, but the IMA level remained unchanged. They suggested that MDA, but not IMA, can be considered as a reliable marker of oxidative damage.

Another study found different results than ours and other mentioned studies. They compared IMA and albumin-adjusted IMA in hyperthyroid, euthyroid and hypothyroid groups. IMA levels were significantly lower in the hypothyroid subjects than the other groups. They attributed this finding to studying with albumin-adjusted IMA, hypoalbuminemia, and hypometabolic state of hypothyroidism. ${ }^{22}$ All mentioned studies were designed in the adult populations; whereas, the population of this study was composed of children.

Uçaktürk et al.studied SHT and dynamic thiol/disulfide balance but not IMA in children. ${ }^{23}$ Their data support the present findings in that they found no significant difference between children with non-autoimmune SHT and the healthy group with respect to dynamic thiol/disulfide balance. The investigators addressed the need for future studies to assess oxidative damage in patients with non-autoimmune SHT in childhood.

Another study on thiol/disulfide metabolism and subclinical hypothyroidism in adults showed that subclinical hypothyroidism caused disulfide formation. That study also found a correlation between antibody levels and thiol oxidation. The authors of that study stated that the mechanism was not clear. Although their data contradict with our findings, one must consider that that study was conducted with adults. ${ }^{24}$ Cheserek et al. studied total antioxidant capacity in $\mathrm{SHT}^{25}$ Total antioxidant capacity was found similar in SHT and euthyroid controls. The two above-mentioned studies support the present data.

This study has several limitations. The sample size is small, and the levels of thyroid antibodies were unknown. Moreover, the study population was heterogeneous. Furthermore, the study design was cross-sectional and follow-up of thyroid hormone levels was lacking. The status of thyroid antibody levels was not completely available. However, the present study may be the first to evaluate IMA in children with SHT. This issue may be important forchildhood thyroid diseases.

\section{CONCLUSION}

This study showed that subclinical hypothyroidism did not affect dynamic thiol/disulfide balance. However, the level of ischemia-modified albumin, a novel ischemic marker, was higher than healthy controls. Subclinical hypothyroidism may be related to the impairment ofIMA, and have a neutral effect on thiol/disulfide balance. Further investigations are needed to clarify the mechanism of the relationship between oxidative damage, ischemia, and subclinical hypothyroidism.

\section{ETHICALAPPROVAL:}

Ethics Committee of Kırıkkale University, Institutional Review Board had approved the study. Date:16.05.2017 Number: $12 / 23$

\section{PATIENTS' CONSENT}

The consent forms were obtained from the parents of all patients.

\section{CONFLICT OF INTEREST:}

Authors declared no conflict of interest.

\section{AUTHORS' CONTRIBUTIONS:}

ST: Design, literature search, data collection and processing, interpretation of data, writing the article.

AA, ATE: Literature search, data collection.

IK: Literature search, analysis and interpretation of data.

SN, OE: Studied the collected samples in biochemistry laboratory.

\section{REFERENCES}

1. Gawlik A, Such K, Dejner A, Zachurzok A, Antosz A, Malecka-Tendera E. Subclinical Hypothyroidism in Children and Adolescents: Is it Clinically Relevant? Int J Endocrinol 2015; 2015:1-12.

2. Gallizzi R, Crisafulli C, Aversa T, Salzano G, De Luca F, Valenzise $M$, et al. Subclinical hypothyroidism in children: İs it always subclinical? Ital J Pediatr 2018; 44(1):25

3. Alpcan A, Törel Ergür A, Tursun S. Çocukluk çağının gizli tehlikesi; subklinik hipotiroidi. Ortadogu Med J 2017; 9(1):34-8.

4. Cremers CM, Jakob U. Oxidant sensing by reversible disulfide bond formation. I Biol Chem 2013; 288(37): 26489-96.

5. Seshadri RV, Sethi S, Gupta N, Agrawal P, Chander SR. Significance of ischemia-modified albumin as simple measure of oxidative stress and discriminatory ability in diabetic rethinopathy. Literature review and meta-analysis. Retina 2016;36(6):1049-57.

6. Hazini A, Cemek M, Işıldak I, Alpdagtas S, Onul A, Unal Ş, et al. Investigation of ischemia modified albumin, oxidant and antioxidant markers in acute myocardial infarction. Postepy kardiol interwencyjnej 2015;11(4):298-303.

7. Gulpamuk B, Tekin K, Sonmez K, Inanc M, Neselioglu S, Erel $\mathrm{O}$, et al. The significance of thiol/disulfide homeostasis and ischemia-modified albumin levels to assess the oxidative stress in patients with different stages of diabetes mellitus. Scand J Clin Lab Invest 2018;78(1-2):136-42.

8. Bundak R, Furman A, Gunoz H, Darendeliler F, Bas F, Neyzi O. Body mass index references for Turkish children. Acta Paediatr 2006; 95(2):194-8.

9. Salerno M, Capalbo D, Cerbone M, De Luca F. Subclinical hypothyroidism in childhood - current knowledge and open issues. Nat Rev Endocrinol 2016; 12(12):734-46.

10. Erel O, Neselioglu S. A novel and automated assay for thiol/disulphide homeostasis. Clin Biochem 2014; 47 (18):326-32.

11. Bar-Or D, Lau E, Winkler JV. A novel assay for cobalt- 
albumin binding and its potential as a marker for myocardial ischemia-a preliminary report. J Emerg Med 2000; 19(4):311-15.

12. Liguori I, Russo G, Curcio F, Bulli G, Aran L, Della-Morte D, et al. Oxidative stress, aging, and diseases. Clin Interv Aging 2018; 13:757-72.

13. Sinha MK, Gaze DC, Tippins JR, Collinson PO, Kaski JC. Ischemia modified albumin is a sensitive marker of myocardial ischemia after percutaneous coronary intervention. Circulation 2003; 107(19):2403-5

14. Yang F, Ma L, Zhang L, Wang Y, Zhao C, Zhu W, et al. Association between serum lipoprotein-associated phospholipase A2, ischemic modified albumin and acute coronary syndrome: A cross-sectional study. Heart Vessels 2019; 34(10):1608-14

15. Pan D, Li D. Role of ischemia-modified albumin in patients with acute decompensated heart failure. Anadolu Kardiyol Derg 2015; 15(8):618-9.

16. Yavuz F, Biyik M, Asil M, Dertli R, Demir A, Polat $H$, et al. Serum ischemic modified albumin (IMA) concentration and IMA/albumin ratio in patients with hepatitis B-related chronic liver diseases. Turkish J Med Sci 2017; 47(3): 947-53.

17. Balamir I, Ates I, Topcuoglu C, Turhan T. Association of Endocan, Ischemia-Modified Albumin, and hsCRP Levels With Endothelial Dysfunction in Type 2 Diabetes Mellitus. Angiology 2018; 69(7):609-16.

18. Huang QX, Ma J, Wang YS. Significance of preoperative ischemia- modified albumin in operable and advanced gastric cancer. Cancer Biomark 2018; 22(3):477-85.

19. Doğan HO, Meriç Yılmaz F, Topçuoğlu C, Berker D, Koca Y. Investigation of the relationship between tsh and serum lipids in patints with subclinical hypothyroidism and euthroid subjects. Cumhur Med J 2016; 38:110-8.

20. Reddy SV, Suchitra MM, Pradeep V, Alok S, Suresh V, Bitla $A R$, et al. Ischemia-modified albumin levels in overt and subclinical hypothyroidism. J Endocrinol Invest 2015; 38 (8):885-90.

21. Erem C, Suleyman AK, Civan N, Mentese A, Nuhoglu I, Uzun $A$, et al. The effect of L-thyroxine replacement therapy on ischemia-modified albümin and malondialdehyde levels in patients with overt and subclinical hypothyroidism. Endocr Res 2016; 41(4):350-60.

22. Oncel M, Kiyici A, Onen S. Evaluation of the Relationship Between Ischemia-Modified Albumin Levels and Thyroid Hormone Levels. J Clin Lab Anal 2015; 29(6):427-31.

23. Uçaktürk SA, Allşlk M, Uǧur Ç, Elmaoğullarl S, Mengen E, Erel Ö. Dynamic Thiol/Disulphide Homeostasis in Children and Adolescents with Non-Autoimmune Subclinical Hypothyroidism. Med Princ Pract 2018; 27(1):44-8.

24. Ates I, Altay M, Yilmaz FM, Topcuoglu C, Neselioglu S, Erel $O$, et al. Dynamic thiol/disulfide homeostasis in patients with autoimmune subclinical hypothyroidism. Endocr Res 2016; 41(4):343-9.

25. Cheserek MJ, Wu GR, Ntazinda A, Shi YH, Shen LY, Le GW. Association between Thyroid Hormones, Lipids and Oxidative Stress Markers in Subclinical Hypothyroidism. J Med Biochem 2015; 34(3):323-31. 